\title{
MUTAÇÃO CONSTITUCIONAL E A AMPLIAÇÃO DE PODERES DO (E PELO) PODER JUDICIARIO: REFLEXÕES ACERCA DOS VOTOS DOS MINISTROS GILMAR MENDES E EROS GRAU NA RCL No $\mathbf{4 3 3 5}^{1}$
}

\author{
CONSTITUCIONAL MUTATION AND THE INCREASE OF POWER OF THE (AN BY \\ THE) JUDICIAL POWER: REFLECTIONS ABOUT THE VOTES OF THE JUDGES \\ GILMAR MENDES AND EROS GRAU, MINISTERS OF THE SUPREME COURT, IN RCL \\ $N^{o} 4335$
}

\begin{abstract}
Bruno Taufner Zanotti
Doutorando pela Faculdade de Direito de Vitória. Coordenador da Extensão do Instituto Direito e professor no Curso de Pós-Graduação Lato Sensu em Direito Público da Fundação Getúlio Vargas (FGV-RJ). E-mail: brunotaufner@hotmail.com

Alexandre de Castro Coura

Pós-doutor como visiting scholar na American University Washington College of Law e visiting foreign judicial fellow no Centro Judiciário Federal em Washington D.C. Professor do Programa de Pós-graduação Stricto Sensu - Mestrado e Doutorado - da Faculdade de Direito de Vitória (FDV) e Promotor de Justiça no Estado do Espírito Santo. E-mail: Acastrocoura@gmail.com
\end{abstract}

Recebido em: 16/05/2016

Aprovado em: 05/07/2016

Doi: $10.5585 / \mathrm{rdb} . v 14 i 6.390$

RESUMO: Objetiva-se, a partir da problematização da mutação constitucional do art. 52, inciso X, da Constituição Federal, verificar a legitimidade dos votos dos Ministros Gilmar Mendes e Eros Grau, proferidos na Rcl n ${ }^{\circ} 4335$, que estava em trâmite no Supremo Tribunal Federal. Com base numa teoria discursiva do Direito, busca-se conhecer e demonstrar algumas consequências nocivas dessa tentativa de implementar um novo modelo de controle de constitucionalidade, que amplia os poderes do próprio órgão que o aplica. Ao longo desse percurso, foram fixadas algumas premissas do paradigma procedimentalista do Estado Democrático de Direito, que abrange o estudo da legitimidade do direito a partir da relação entre soberania popular e direitos fundamentais. Concluiu-se que a posição a favor da mutação constitucional do controle difuso de constitucionalidade viola a autonomia jurídica dos cidadãos, identifica o STF como o único titular do sujeito constitucional e transforma os cidadãos em clientes do pensamento autoritário de alguns poucos magistrados.

Palavras-chave: Controle difuso de constitucionalidade. Mutação constitucional. Soberania popular. Direitos fundamentais.

ABSTRACT: It is intended, from questioning the constitutional mutation of art. 52, X, of the Federal Constitution, to verify the legitimacy of the votes of the judges Gilmar Mendes and Eros Grau, Ministers of the Supreme Court. Based on the discursive theory of Law, we seek to

${ }^{1} \mathrm{O}$ presente artigo é fruto de discussões acadêmicas desenvolvidas entre os coautores, especialmente nas pesquisas e discussões desenvolvidas no Grupo de Pesquisa CNPQ "Hermenêutica Jurídica e Jurisdição Constitucional” ao longo do ano de 2015, no programa de pós-graduação em sentido estrito (doutorado) da Faculdade de Direito de Vitória (FDV).

Revista de Direito Brasileira | São Paulo, SP | v. 14 | n. 6 | p. 173 - 185 | maio/ago. 2016 
demonstrate some harmful consequences of this attempt to introduce a new model of judicial review, which increases the powers of the Court that would apply the theory. Along the way, the premises of a democratic legal state paradigm were set, which includes the study of legitimacy of Law from the relationship between popular sovereignty and fundamental rights. We were able to reach the following conclusion: the constitutional mutation of the judicial review violates the legal autonomy of citizens, the Supreme Court is identified as the sole owner of the constitutional subject and the citizens were transformed into clients of the authoritarian thinking of a few judges.

Keywords: Judicial Review. Constitutional mutation. Popular sovereignty. Fundamental rights.

SUMÁRIO: Introdução. 1. Os votos dos Ministros Gilmar Mendes e Eros Grau: uma defesa da mutação constitucional do art. 52, inciso X, da Constituição Federal. 2. A coesão interna entre soberania popular e direitos fundamentais: uma leitura procedimental do Estado Democrático e Direito 3. A Reclamação $\mathrm{n}^{\circ} 4335$ e a atuação do Poder Judiciário como superego de uma sociedade órfã. Considerações finais. Referências.

\section{INTRODUÇÃO}

O Supremo Tribunal Federal, nos últimos anos, tem revisto sua posição em muitos aspectos do controle de constitucionalidade, seja no modelo difuso, seja no concentrado. É nesse contexto que se insere o problema deste artigo, já que, em nome do incremento da defesa do sistema de direitos e garantias fundamentais, alguns Ministros do Supremo Tribunal Federal parecem se colocar em concorrência direta com o Poder Constituinte Originário, violando as autonomias jurídicas dos cidadãos.

Estava em trâmite a RCL n ${ }^{\circ}$ 4335, que tinha por finalidade consubstanciar uma mutação constitucional ao art. 52, inciso X, da Constituição Federal. Os Ministros Gilmar Mendes e Eros Grau, os primeiros magistrados a se manifestarem na ação, defendiam que a disposição constitucional havia sofrido uma mutação constitucional, capaz de alterar o papel do Senado no controle difuso de constitucionalidade. A ação teve o seu julgamento encerrado em meados de 2014 e os Ministros foram votos vencidos; contudo, é importante analisar a proposta e verificar a sua repercussão no ordenamento jurídico brasileiro, caso fosse a tese vencedora. Afinal, o voto vencido, em vez de ser esquecido, deve ser valorizado e levado ao debate público (PRATES, 2004, p. 548).

Com base nessas considerações iniciais, questiona-se: diante da possível ocorrência dessa suposta mutação, não estariam os citados Ministros desarticulando todo um sistema de direitos e garantias fundamentais, que parte da supremacia da Constituição Federal, devidamente interligado com o exercício da soberania popular? Para tanto, são lançados os seguintes questionamentos secundários: Como ocorre, no Estado Democrático de Direito, a relação entre soberania popular e direitos fundamentais? Qual a linha divisória entre o legítimo exercício da hermenêutica e a usurpação do espaço reservado ao exercício da soberania popular?

Com a finalidade de responder os questionamentos e melhor integrar as fontes de estudo, verificou-se a necessidade de uma abordagem hermenêutica. Por meio da interpretação das diversas fontes do Direito, será possível responder os problemas levantados, de forma a possibilitar a análise de como uma hermenêutica equivocada é capaz de violar direitos fundamentais. Portanto, o tipo de pesquisa a ser utilizado será o exploratório pelo fato de o tema envolver diretamente a análise bibliográfica. Ademais, foi escolhida a técnica de estudo de caso para analisar a Rcl no 4335, em especial os votos dos Ministros Gilmar Mendes e Eros Grau.

Com base na metodologia apresentada, no primeiro capítulo, serão analisados os votos 
dos Ministros Gilmar Mendes e Eros Grau, para que, no segundo capítulo, seja desenvolvida a relação entre soberania popular, direitos e garantias fundamentais e sociedade aberta de intérpretes das normas constitucionais. Tais fundamentos servirão de base para o terceiro capítulo, no qual serão abordadas as consequências jurídicas da mutação constitucional do art. 52, inciso X, da Constituição Federal, tal como defendida pelos Ministros, bem como o impacto de tal tese na identidade do sujeito constitucional.

\section{OS VOTOS DOS MINISTROS GILMAR MENDES E EROS GRAU: UMA DEFESA DA MUTAÇÃO CONSTITUCIONAL DO ART. 52, INCISO X, DA CONSTITUIÇÃO FEDERAL}

A fim de entender os votos dos Ministros Gilmar Mendes e Eros Grau, faz-se necessária uma breve explanação sobre o funcionamento do controle de constitucionalidade no Brasil, em especial sobre a atribuição do Senado a partir da previsão constitucional do art. 52, inciso X, da Constituição Federal.

O controle difuso de constitucionalidade possibilita que qualquer magistrado ou Tribunal analise, no caso concreto, a constitucionalidade de determinada lei ou ato normativo. Isso ocorre, porque a Jurisdição brasileira, influenciada pelo paradigma do Estado Democrático de Direito, não se presta a uma atuação desgarrada das normas constitucionais. É por isso deve-se pensar na Jurisdição como uma Jurisdição Constitucional, ou seja, tendo como limites e possibilidades hermenêuticas as normas constitucionais:

como o controle de constitucionalidade é incumbência funcional de todos os juízes no Brasil, o que inclui não apenas negar aplicação às normas inconstitucionais, como também interpretar conforme a Constituição, promovendo ativamente a efetivação dos direitos e garantias fundamentais a cada decisão, toda jurisdição é jurisdição constitucional (COURA, 2008, p. 312).

Os efeitos da decisão final proferida no controle difuso de constitucionalidade, como regra, somente atingem as partes do processo, seja em primeira instância, seja mediante recurso. Em outras palavras, a inaplicabilidade da lei se restringe àquele caso concreto em que foi declarada inconstitucional, continuando plenamente válida no ordenamento jurídico e obrigatória para todos.

O efeito erga omnes de tais decisões em controle difuso de constitucionalidade somente é alcançado quando o Supremo Tribunal Federal aplica o art. 52, inciso X, da Constituição Federal, hipótese em que ocorre o Senado poderá suspender a execução, no todo ou em parte, de lei declarada inconstitucional por decisão definitiva do Supremo Tribunal Federal.

Não obstante, essa competência constitucional quase foi sensivelmente alterada por ocasião do julgamento da Rcl n 4335, uma vez que os Ministros Gilmar Mendes e Eros Grau sustentavam a existência de uma mutação constitucional ao art. 52, inciso X, da Constituição Federal. Em síntese, esse posicionamento conferia efeito erga omnes e vinculante a todos os julgados proferidos pelo Pleno do Supremo Tribunal Federal, mesmo que em controle difuso de constitucionalidade, outorgando ao Senado o mero papel de dar publicidade ao que foi decidido. De um lado, os Ministros ampliam seus poderes inerentes à Jurisdição Constitucional, e, de outro lado, o Senado tem sua atribuição reduzida, ao fundamento de que sua inércia na utilização do art. 52, inciso X, da Constituição é suficiente para modificar todo o funcionamento do controle de constitucionalidade: 
De acordo com a doutrina tradicional, a suspensão da execução pelo Senado do ato declarado inconstitucional pelo STF seria ato político que empresta eficácia erga omnes às decisões definitivas sobre inconstitucionalidade proferidas em caso concreto. Asseverou, no entanto, que a amplitude conferida ao controle abstrato de normas e a possibilidade de se suspender, liminarmente, a eficácia de leis ou atos normativos, com eficácia geral, no contexto da $\mathrm{CF} / 88$, concorreram para infirmar a crença na própria justificativa do instituto da suspensão da execução do ato pelo Senado, inspirado numa concepção de separação de poderes que hoje estaria ultrapassada (Rcl 4335/AC, rel. Min. Gilmar Mendes, $1^{\circ}$ de fevereiro de 2007, Inf. 454 do STF).

O Ministro Gilmar Ferreira Mendes, relator da RCL no 4335, reconhece a importância da atuação do Senado como coordenador dos poderes, por meio da suspensão da lei declarada inconstitucional pelo STF nas Constituições anteriores; contudo, entende que o atual sistema constitucional não mais comportaria a aplicação do art. 52, inciso X, da Constituição Federal.

Inicialmente, o relator (MENDES, p. 25-27) fundamenta a atual existência do mencionado inciso em uma causa exclusivamente histórica e complementa que a previsão constitucional não possui aplicabilidade em diversos casos: (a) na declaração de inconstitucionalidade parcial sem redução de texto; (b) quando utiliza a técnica da interpretação conforme; (c) na declaração de inconstitucionalidade de norma ainda constitucional; e (d) quando somente fixa uma determinada interpretação sem retirar a norma do sistema, e muitas outras ${ }^{2}$.

Nessa linha de pensamento, o Ministro (MENDES, p. 30) trata de algumas hipóteses em que a declaração de inconstitucionalidade pelo Pretório Excelso no controle difuso possui aplicação imediata nos demais Tribunais, dispensando a aplicação da cláusula de reserva de plenário (art. 97 da Constituição Federal). A partir de tal argumentação, o ministro apontar a sua primeira conclusão parcial:

Esse entendimento marca uma evolução no sistema de controle de constitucionalidade brasileiro, que passa a equiparar, praticamente, os efeitos das decisões proferidas nos processos de controle abstrato e concreto. A decisão do Supremo Tribunal Federal, tal como colocada, antecipa o efeito vinculante de seus julgados em matéria de controle de constitucionalidade incidental, permitindo que o órgão fracionário se desvincule do dever de observância da decisão do Pleno ou o Órgão Especial do Tribunal a que se encontra vinculado. (MENDES, p. 30)

Ademais, com base no crescimento do controle abstrato de constitucionalidade promovido pelo Poder Legislativo após 1988, como a ampliação dos entes legitimados a provocar o controle abstrato, a equiparação entre Ação Direta de Inconstitucionalidade e Ação Direta de Constitucionalidade, a criação da Arguição de Descumprimento de Preceito Fundamental, concluiu o Ministro Gilmar Mendes que o controle de constitucionalidade em franco crescimento é o concentrado, invertendo a lógica de predominância do controle difuso até então existente.

Em razão de todo o exposto e fundamentado nas diversas modificações legislativas e jurisprudências acima citadas, conclui o Ministro Gilmar Ferreira Mendes (p. 52) que:

É possível, sem qualquer exagero, falar-se aqui de uma autêntica mutação constitucional em razão da completa reformulação do sistema jurídico e, por conseguinte, da nova compreensão que se conferiu à regra do art. 52, X da

\footnotetext{
${ }^{2}$ Nesses casos, como defendem Streck, Cattoni e Lima (p. 12), o STF somente fixa o sentido constitucional das normas, sendo que a atribuição do Senado se restringe à suspensão das normas inconstitucionais.
}

Revista de Direito Brasileira | São Paulo, SP | v. 14 | n. 6 | p. 173 - 185 | maio/ago. 2016 
Constituição de 1988. Valendo-nos dos subsídios da doutrina constitucional a propósito da mutação constitucional, poder-se-ia cogitar aqui de uma autêntica reforma da Constituição sem expressa modificação do texto.

A suposta mutação constitucional ao art. 52, inciso $\mathrm{X}$, teria por finalidade alterar a atribuição do Senado. Da relevante atribuição de suspensão da execução da lei declarada inconstitucional, o Senado passa a ser um mero publicador das decisões do Supremo Tribunal Federal. O resultado, portanto, é uma abstrativização do controle difuso de constitucionalidade ao aproximar este modelo de controle daquele efetuado no controle concentrado pelo STF.

O voto do Ministro Eros Grau (p. 11) segue a linha de pensamento do Relator ao entender que a práxis do Supremo Tribunal Federal é capaz de revogar dispositivos constitucionais e, com base nesse fundamento, admite a existência de uma mutação no referido texto constitucional capaz de revogá-lo sem qualquer alteração formal pelo Poder Constituinte Derivado. Eis a possível nova redação sugerida pelo Ministro Eros Grau (p. 11) ao art. 52, inciso $\mathrm{X}$, da Constituição Federal: "compete privativamente ao Senado Federal dar publicidade à suspensão da execução, operada pelo Supremo Tribunal Federal, de lei declarada inconstitucional, no todo ou em parte, por decisão definitiva do Pleno".

A Rcl no 4335 teve sua tramitação iniciada em 2007 e foi somente em meados de 2014 que a ação teve o seu julgamento finalizado. Todos os demais votos foram em sentido contrário. No entanto, faz-se necessário entender e analisar a amplitude da hermenêutica sustentada pelos Ministros Gilmar Mendes e Eros Grau dentro de um Estado Democrático de Direito. Até que ponto uma interpretação dessa estirpe não vai de encontro aos direitos e garantias individuais, em arrepio à Constituição Federal?

\section{A COESÃO INTERNA ENTRE SOBERANIA POPULAR E DIREITOS FUNDAMENTAIS: UMA LEITURA PROCEDIMENTAL DO ESTADO DEMOCRÁTICO DE DIREITO}

Para responder o questionamento levantado, faz-se necessário analisar a relação entre soberania popular, poder constituinte, direitos fundamentais e supremacia constitucional. A partir de Habermas, verificar-se-á de que modo esses institutos se entrelaçam para formar o medium necessário para o adequado funcionamento do Estado Democrático de Direito.

Ao se iniciar um novo ordenamento jurídico, o exercício da soberania popular se dá por meio do Poder Constituinte Originário, o qual estabelece os direitos fundamentais a serem positivados na Constituição Federal. A relação entre soberania popular e direitos fundamentais não se esgota neste momento e, em Habermas (2007, p. 294), diz respeito à coesão entre Estado de Direito e Democracia, que possui basicamente quatro pontos de análise: a) o atual conceito do Direito, b) a legitimidade do Direito, c) a relação entre soberania popular e direitos humanos e d) o aparente conflito entre autonomia privada e autonomia pública.

O atual conceito do Direito é construído, de um lado, pelo respeito ao seu caráter coercitivo e, por outro lado, pela sua necessidade intrínseca e fundamental de garantir direitos fundamentais, em especial os direitos à liberdade e à igualdade. O Estado, ao instrumentalizar a lei, impõe unilateralmente a coercitividade do Direito por ser o único agente legitimado a fazer o uso legal da força. Afinal, a imposição de sanções se legitima na lei, e esta no devido processo legislativo para sua criação. Do mesmo modo, o Estado também garante, por meio das leis, os direitos fundamentais dos cidadãos. O cumprimento das leis, mesmo que coercitivamente, é um instrumento para garantir o direito a todos, deixando como espaço para atuação das pessoas tudo o que não for vedado pela lei.

Esse duplo aspecto conceitual do Direito reclama uma análise de sua legitimidade, em Revista de Direito Brasileira | São Paulo, SP | v. 14 | n. 6 | p. 173 - 185 | maio/ago. 2016 
especial quando "bons ativismos" judiciais são sustentados para supostamente ampliar a proteção aos direitos e garantias fundamentais, tal como ocorre no caso da mutação constitucional do art. 52, inciso X, da Constituição Federal. Acontece que, da forma que o fundamento foi exposto, a alegação dos Ministros Gilmar Mendes e Eros Grau se aproxima mais de uma alegação moral do que jurídica, como será demonstrado mais a frente.

Habermas (2007, p. 296) refuta a legitimidade do direito na moral, ao afirmar que o "direito moderno, em razão do seu caráter formal, exime-se em todo caso de qualquer ingerência direta que advenha de uma consciência moral remanescente e pós-tradicional”.

$\mathrm{O}$ autor trata de tal questão ao analisar os direitos subjetivos. Esses direitos foram introduzidos com a finalidade de garantir um espaço privado à sociedade, ao argumento de que às pessoas é permitido fazer tudo o que não for pela lei proibido. Contudo, a moral não compactua com esse modelo, já que, na moral, qualquer espaço, mesmo privado, é regrado por uma simetria entre direitos e deveres.

Observa-se, portanto, que o Direito não se confunde com a moral. Pelo contrário, são campos de atuação distintos. Contudo, não se pode concluir que, em Habermas, não exista qualquer relação entre direito e moral, tanto que o autor pondera que

[...] uma ordem jurídica só pode ser legítima, quando não contrariar princípios morais. Através dos componentes de legitimidade de validação jurídica, o direito adquire uma relação com a moral. Entretanto, essa relação não deve levar-nos a subordinar o direito à moral, no sentido de uma hierarquia de normas (HABERMAS, 2003a, p. 140-141).

Existe uma relação de complementação recíproca entre direito e moral, pois analisam o mesmo problema (a solução de conflitos) de ângulos distintos. Por um lado, a moral é um mero sistema de conhecimento; por outro lado, o Direito traz em si uma coercitividade estatal que não existe na moral (HABERMAS, 2003, p. 141).

Ademais, é impossível rechaçar a carga moral presente nos direitos humanos (ou fundamentais), mas sua interpretação e aplicação são decorrência da "autodeterminação democrática dos cidadãos", devendo ser eles interpretados "como direitos jurídicos, não obstante seu conteúdo moral" (HABERMAS, 2003, p. 140). É por isso que, apesar de complementares, o direito não se legitima na moral. A moral será um componente que integrará o Direito por meio da mencionada autodeterminação democrática dos cidadãos.

Assim, "o direito legitima-se [...] como um meio para o asseguramento equânime da autonomia pública e privada" (HABERMAS, 2007, p. 298). O direito, portanto, é o fundamento de si mesmo, não obstante o conteúdo moral dos direitos fundamentais. No paradigma procedimentalista do Estado Democrático de Direito, o Direito, à luz da teoria do discurso, ao institucionalizar as formas comunicativas de formação da vontade, legitima o resultado final do procedimento, o que possibilita que os destinatários das normas sejam também os autores de sua criação (CATTONI, 2006, p. 139).

Em outras palavras, a legitimidade do direito decorre da coesão direta existente entre soberania popular e direitos fundamentais (ou direitos humanos):

A autonomia política dos cidadãos deve tomar corpo na auto-organização de uma comunidade que atribui a si mesma suas leis, por meio da vontade soberana do povo. A autonomia privada dos cidadãos, por outro lado, deve afigurar-se nos direitos fundamentais que garantem o domínio anônimo das leis. (HABERMAS, 2007, p. 299)

A legitimidade do Direito, no plano público, decorre do exercício da soberania popular, 
ao passo que, no plano privado, a legitimidade decorre do exercício dos direitos fundamentais.

Desse modo, somente mediante o respeito aos direitos fundamentais, quando analisado como decorrência do respeito à autodeterminação como prerrogativa da soberania popular, será possível uma relação entre autonomia pública (autores das normas jurídicas), autonomia privada (destinatários das normas jurídicas) e a atuação do Poder Judiciário. E essa é a questão que norteia o presente artigo.

É o agir comunicativo que possibilita os cidadãos, naturais destinatários das normas e dos direitos, de se verem como seus autores (HABERMAS, 2007, p. 301). Assim, verifica-se mais um fundamento para que a moral não seja a fonte de legitimidade do Direito. Como os fatos morais são anteriores aos cidadãos e previamente dados, esses cidadãos não podem ser qualificados como os seus autores. No paradigma procedimentalista do Estado Democrático de Direito, ao contrário, a eleição das normas e dos direitos ocorre de acordo com as necessidades da população e de acordo com as escolhas desta. Em síntese, diferentemente da moral, no Direito, os cidadãos são autores da criação dos direitos e a eles se submetem como naturais destinatários.

Com base nesse viés, possibilita-se a coesão entre soberania popular e direitos fundamentais. A soberania popular - espaço da autonomia pública - reclama o exercício dos direitos humanos (ou direitos fundamentais) para o seu adequado exercício, ao passo que os direitos fundamentais - espaço da autonomia privada - necessitam da soberania popular para determinar o modo pelo qual tais direitos serão exercidos. Trata-se da coesão interna entre direitos fundamentais e soberania popular, que também pode ser observada nas seguintes palavras de Habermas (2007, p. 301):

Portanto, sem os direitos fundamentais que asseguram a autonomia privada dos cidadãos, não haveria tampouco um medium para a institucionalização jurídica das condições sob as quais eles mesmos podem fazer uso da autonomia pública ao desempenharem seu papel de cidadãos do Estado. Dessa maneira, a autonomia privada e a pública pressupõem-se mutuamente, sem que os direitos humanos possam reivindicar um privado sobre a soberania popular, nem essa sobre aquele.

Em razão do exposto, uma visão procedimentalista do Estado Democrático de Direito possibilita uma convivência harmônica entre Constituição e Democracia, decorrência natural da coesão interna existente entre soberania popular e direitos fundamentais, conquista esta inviável nos paradigmas anteriores.

No Estado Liberal, a Constituição era qualificada como um instrumento de proteção dos direitos de primeira geração (liberdades negativas), voltada para a defesa de uma esfera privada burguesa. No Estado Social, a Constituição se concretizava na medida em que os direitos positivos eram homogeneamente materializados na sociedade órfã a espera de um Estado paternalista e clientelista. (CATTONI, 2006, p. 112)

A Democracia, por sua vez, no Estado Liberal, era o locus que deveria garantir a "justa" disputa do mercado, sempre vinculada à garantia dos interesses da classe burguesa. No Estado Social, a preocupação da Democracia era a produção em massa de direitos sociais, sem a participação dos grupos afetados nas tomadas de decisão. (CATTONI, 2006, p. 112-113)

No Estado Liberal e no Estado Social, os direitos fundamentais eram qualificados como verdadeiras limitações externas à soberania popular, devendo esta agir de acordo com os Direitos preponderantes em cada paradigma. Ao contrário, no Estado Democrático de Direito, os direitos fundamentais não são causas limitadores ao exercício da soberania popular, uma vez que os dois são cooriginários em razão da coesão interna entre autonomia pública e autonomia privada. É por isso que a coesão entre Constituição e Democracia traduz-se na mediação entre direitos fundamentais e soberania popular. 
Um processo judicial democrático consiste em instrumento da Democracia, ao ser analisado como espaço da autonomia pública, mas necessário para o adequado respeito à autonomia privada. No processo judicial, a interpretação consiste na principal atividade desenvolvida pelo juiz, uma vez que, ao decidir uma causa, necessariamente, deve utilizar-se da hermenêutica, não se podendo falar na suficiência da lei ou mesmo numa interpretação discricionária pelo magistrado.

É muito comum verificar em julgados que a interpretação é um evento exclusivamente estatal e a mutação constitucional sustentada pelos Ministros Gilmar Mendes e Eros Grau se inserem nesse contexto ao apresentarem votos que, inclusive, refutam a validade de dispositivo constitucional criado pelo poder constituinte originário, decorrência direta da participação popular em 1988. Com isso, os Ministros violam a autonomia pública e, por via reflexa, tal como explicado acima, a autonomia privada ao partirem do pressuposto de que os seus votos são capazes de sustentar qualquer conclusão por serem Ministros da Suprema Corte. Essa ideia tem por base o que Peter Häberle chama de "sociedade fechada de intérpretes", ou seja, os intérpretes constitucionais em sentido estrito, sem possibilidade de uma abertura popular e democrática.

É necessária uma mudança nas premissas da interpretação no curso de um processo judicial. A hermenêutica deve se liberar das amarras de uma visão estritamente fechada para se abrir a uma interpretação pluralista e democrática, mais adequada ao Estado Democrático de Direito. A posição de alguns Ministros não deve ser vista como o limite da intepretação. Buscase, portanto, uma sociedade aberta de intérpretes da Constituição e o constante respeito à soberania popular.

Com o intuito de sustentar essa abertura hermenêutica, Häberle (1997, p. 20-22) sugere um catálogo dos inúmeros potenciais intérpretes constitucionais, como as decisões estatais administrativas ou judiciais, os sujeitos que atuam nos processos (autor, réu, audiências públicas, peritos, pareceristas, amicus curiae, e outros), a opinião pública, a imprensa, os participantes do processo legislativo, bem como qualquer indivíduo que viva a norma. Assim, não há que se falar em uma lista previamente estabelecida ou em um elenco taxativo de intérpretes, o que iria de encontro a sua teoria; pelo contrário, fala-se em um catálogo cujas possibilidades não se esgotam, mas são criadas e ampliadas diariamente:

A análise até aqui desenvolvida demonstra que a interpretação constitucional não é um evento exclusivamente estatal, seja do ponto de vista teórico, seja do ponto de vista prático. A esse processo têm acesso potencialmente todas as forças da comunidade política. O cidadão que formula um recurso constitucional é intérprete da Constituição tal como o partido político que propõe um conflito entre órgãos (HÄBERLE, 1997, p. 23).

Durante uma entrevista de Peter Häberle (2009, p. 137) a Zvonko Posavec, o autor faz uma importante leitura de sua proposta:

Isso significa que não só os juristas interpretam a constituição, mas também qualquer cidadão comum dentro de uma democracia cidadã. Essas contribuições para o entendimento da Constituição as realiza, consciente ou inconscientemente, em sua vida, a longo prazo.

A partir do momento em que se visualiza o povo como um elemento qualitativo - e não mais como elemento meramente quantitativo -, percebe-se a grande abertura interpretativa que a Jurisdição Constitucional oferece num Estado Democrático de Direito. Tendo por base esse fundamento, é possível afirmar que "a sociedade é livre e aberta na medida em que se amplia o círculo dos intérpretes da Constituição” (HÄBERLE, 1997, p. 40). 
Os anseios sociais e populares, a partir dessa perspectiva, ganham relevância na construção de uma interpretação pluralista e aberta, bem como passam a compor a identidade do sujeito constitucional. A construção e reconstrução da identidade do sujeito constitucional integra substancialmente o critério qualitativo do "povo" e possibilita a repercussão prática nas normas constitucionais (ROSENFELD, 2003, p. 36 e 37). Não se pode admitir qualquer exclusão social desse círculo hermenêutico, que parte da coesão entre soberania popular e direitos fundamentais, e se amplia diariamente à luz de uma teoria procedimental que possibilita a participação de todos os afetados.

Em face de tudo o que foi exposto, não se pode negar que o exercício legítimo de uma Jurisdição Constitucional requer, necessariamente, uma mudança de postura, em especial dos Ministros Gilmar Mendes e Eros Grau. Uma sociedade aberta de intérpretes das normas constitucionais possibilita, dentro do processo judicial, um primeiro passo para uma mediação entre soberania popular e direitos fundamentais. Com isso, as normas constitucionais ganham substancial relevância e a identidade do sujeito constitucional não se confunde com a atuação de alguns Ministros do Supremo Tribunal Federal.

\section{A RECLAMAÇÃO N $^{\circ} 4335$ E A ATUAÇÃO DO PODER JUDICIÁRIO COMO SUPEREGO DE UMA SOCIEDADE ÓRFÃ}

Em vez de o Poder Judiciário voltar suas atitudes para a democratização do processo, forçando a participação popular; no caso da mutação constitucional, a decisão quase foi tomada a partir de premissas pessoais de dois julgadores, sem embasamento constitucional e democrático. Os Ministros Gilmar Mendes e Eros Grau, com base nos votos proferidos na RCL n⿳ 4335 , utilizam como discurso a majoração da segurança pública e dos direitos fundamentais para revogar dispositivos constitucionais, como se fossem censores da soberania popular.

$\mathrm{Na}$ Alemanha, houve um caso semelhante no qual os Ministros do Tribunal Federal Constitucional se declararam competentes para analisar as normas do Poder Constituinte Originário:

O Tribunal Federal Constitucional reconhece a existência de direitos suprapositivos que também vinculam o legislador constitucional, e se declara competente nestes termos para controlar o teor de constitucionalidade do direito vigente.

(...)

Não se é de excluir que uma determinação constitucional seja nula, pelo fato mesmo de ela ser parte da Constituição. Existem fundamentos constitucionais que são basilares e como tais expressão de um direito anterior à Constituição, de modo que vinculam o próprio legislador constitucional, podendo tornar nulos outros dispositivos constitucionais que contra si atentem e não participem da mesma hierarquia. (MAUS, 2000, 191)

Quando essa situação ocorre, Ingeborg Maus pontua que a jurisprudência passa a se apresentar como uma grande obra da personalidade de magistrados, que aparecem, a partir de tal perspectiva, como "deuses do Olimpo do Direito" (MAUS, 2000, 185). Trata-se da tendência ao biografismo dos magistrados, característica de uma sociedade amorfa, pois "o aspecto típico dessas biografias de juízes parece se configurar na ideia [...] de que os pressupostos para uma decisão racional e justa residem na formação da personalidade de juízes” (MAUS, 2000, 185).

$\mathrm{O}$ direito perde o seu caráter emancipador e trata os indivíduos e a coletividade como se meros objetos fossem (MAUS, 2000, p. 185). A sociedade se torna dependente e incapaz de ter 
consciência ampla dos próprios atos. Em razão dessa assertiva, afirma a autora que o crescimento do Poder Judiciário como Terceiro Poder reflete a imagem do pai, profeta ou Deus do Olimpo do Direito (MAUS, 2000, p. 185) e complementa afirmando que, "quando a justiça ascende ela própria à condição de mais alta instância moral da sociedade, passa a escapar de qualquer mecanismo de controle social"' (2000, p. 187).

Por isso, em referência ao pensamento de Maus (2000, p. 189), a fundamentação da decisão dos Ministros nos valores da segurança jurídica e na proteção aos direitos e fundamentais tem caráter unicamente moral e com a finalidade de desvincular do controle popular o conteúdo do que é decidido. Afinal, 'toda menção a um dos princípios 'superiores' ao direito escrito leva quando a Justiça os invoca - à suspensão das disposições normativas individuais e a se decidir o caso de forma inusitada" (MAUS, 2000, p. 189).

A autonomia pública resta claramente violada. A soberania popular é deslocada do processo judicial para o limbo e passa a ser utilizada de acordo com a estratégia de julgamento do magistrado, daí o caráter pragmatista do conteúdo dos votos. Com isso, os Ministros se tornam livres para analisar a constitucionalidade das normas do próprio Poder Constituinte e as normas constitucionais nada mais são do que uma estratégia, que pode ou não ser utilizada a depender da vontade do juiz. Com tal postura, o texto constitucional perde relevo, e a melhor interpretação é aquela preferida pela autoridade do Tribunal Constitucional.

A mutação constitucional do art. 52, inciso X, da Constituição Federal, afeta a gênese democrática do direito, o que reflete num grave deficit de legitimidade. Se a aplicação do direito é decorrência exclusiva do pragmatismo de alguns magistrados, não é possível falar no princípio democrático como fundamento do ordenamento jurídico. A soberania popular perde o seu lugar para uma instituição que se transforma no regente do povo, e o povo transmuta-se do papel de cidadão para o de mero cliente.

Maus (2000, p. 192), nessa perspectiva, compara a atuação dos Ministros com essa postura a de um monarca, afirmando que,

assim como o monarca absoluto de outrora, o tribunal que disponha de tal entendimento do conceito de Constituição encontra-se livre para tratar de litígios sociais como objetos, cujo conteúdo já está previamente decidido na Constituição "corretamente interpretada", podendo assim disfarçar o seu próprio decisionismo sob o manto de uma "ordem de valores" submetida à Constituição.

A Constituição torna-se uma folha de papel de onde os sábios (os magistrados) deduziriam diretamente os principais valores a serem protegidos a qualquer custo (MAUS, 2000, p. 192). Perde-se, com isso, a norma constitucional como instrumento capaz de estruturar o Estado e proteger os direitos fundamentais.

Assim, a jurisprudência do Pretório Excelso ganha mais relevância do que a própria Constituição. A guarda da Constituição é deslocada para a guarda das principais decisões tomadas no passado pelo Supremo Tribunal Federal. Perde-se o caráter democrático e o sentido da Constituição, afetando gravemente a identidade do sujeito constitucional.

A teoria sustentada pelos Ministros Eros Grau e Gilmar Mendes produz graves problemas institucionais e constitucionais. Violam-se a Constituição Federal, o princípio democrático, a soberania popular, a autonomia pública e os direitos fundamentais.

Os efeitos dessa hermenêutica, portanto, repercutem diretamente na identidade do sujeito constitucional brasileiro. Caso a Rcl. $\mathrm{n}^{\mathrm{o}} 4335$ fosse julgada procedente, o Supremo Tribunal Federal atuaria como tutor de uma sociedade órfã, ocupando de forma autoritária um espaço que deveria ser democraticamente estabelecido. No entanto, a identidade do sujeito constitucional é um espaço fluido que não pode ser ocupado de forma totalitária por nenhuma pessoa, órgão ou instituição. Com tal pensamento, Michel Rosenfeld, em seu livro "A Identidade

Revista de Direito Brasileira | São Paulo, SP | v. 14 | n. 6 | p. 173 - 185 | maio/ago. 2016 
do Sujeito Constitucional", rechaça a possibilidade da referida atuação do Pretório Excelso.

O sujeito constitucional é marcado por uma incompletude, por um hiato, sendo produto de um processo dinâmico e contínuo de construção e reconstrução de sua identidade. Essa definição é construída no dia a dia sem nunca chegar ao fim, sendo sempre suscetível de maior precisão e maior definição (ROSENFELD, 2003, p. 23). Esse vazio inicial é "fonte última de legitimidade e autoridade para a ordem constitucional" (ROSENFELD, 2003, p. 26). Como consequência, fazem parte dessa identidade, a partir da teoria do discurso, todos os que integram uma sociedade aberta de intérpretes, inclusive os Tribunais e os órgãos de Poder, pois somente assim os autores das normas poderão se visualizar também como seus destinatários, de modo a se respeitar a coesão entre soberania popular e direitos fundamentais.

O pluralismo, no Estado Democrático de Direito, leva em consideração o outro na construção dessa identidade constitucional, e essa ideia é uma constante no pensamento de Michel Rosenfeld. O vazio inicial deve ser preenchido a partir de tal pressuposto, de modo a utilizar a Constituição como o documento que tenta preencher essa incompletude, apresentandose como um pano de fundo compartilhado:

Na medida em que o constitucionalismo deve se articular com o pluralismo, ele precisa levar o outro na devida conta, o que significa que os constituintes devem forjar uma identidade que transcenda os limites de sua própria subjetividade. [...] A elaboração de uma Constituição pode ser considerada como, sobretudo, uma tentativa de preencher esse vazio, esse hiato, mediante o alcance do outro para forjar uma identidade comum enraizada em um texto constitucional compartilhado (ROSENFELD, 2003, p. 36).

Com base em tal premissa, a tentativa do Pretório Excelso de se identificar como exclusivo sujeito constitucional fere a autonomia pública dos cidadãos, espelhada na soberania popular, que deveria ser articulada dentro de um procedimento democrático à luz da teoria do discurso, respeitando a Constituição Federal e os direitos fundamentais.

\section{CONSIDERAÇÕES FINAIS}

Caso o Supremo Tribunal Federal tivesse julgado procedente a Reclamação $\mathrm{n}^{\circ} 4335$ e admitido a mutação constitucional ao art. 52, inciso X, da Constituição Federal, haveria uma nítida postura de pai ou tutor de uma sociedade órfã, de modo a eliminar a autonomia pública dos cidadãos e violar os seus direitos fundamentais. Essa tutela paternalista rechaça os interlocutores inerentes ao pluralismo, deixando de lado o debate público e negando o povo em seu aspecto qualitativo, ou seja, como verdadeiros intérpretes de uma sociedade aberta.

Esse equívoco era o mesmo existente no Estado Social. O caminhar da modernidade implica na necessidade de um olhar que se volte para trás para que equívocos do passado não sejam repetidos. E pior, ao não se proteger a esfera pública de atuação, restam violados também os direitos fundamentais, em razão da coesão interna existente entre a esfera pública e esses direitos, não se permitindo, assim, um adequado exercício da cidadania.

Nesse ponto reside a principal de diferença entre Estado Social e Estado Democrático de Direito. O primeiro, em razão do caráter eminentemente paternalista, produz pessoas dependentes da iniciativa do Estado e alienadas das questões sociais. O segundo, como decorrência do princípio democrático, deve produzir cidadãos por meio do contínuo exercício da cidadania, transformando o direito em instrumento emancipador, para que as pessoas sejam engajadas nas questões sociais e preocupadas com a formação da vontade geral.

A relação existente entre um Estado Democrático de Direito real (facticidade) e o ideal

Revista de Direito Brasileira | São Paulo, SP | v. 14 | n. 6 | p. 173 - 185 | maio/ago. 2016 
(validade) forma uma produtiva tensão, necessária para construir a identidade do sujeito constitucional e capaz de emancipar o cidadão. A Modernidade é um projeto inacabado, que continuará a se desenvolver no futuro; por isso, o caminhar natural do constitucionalismo e do Direito, em especial pela sociedade plural e complexa na qual os magistrados estão inseridos, necessita de uma teoria que não se esgote na visão pessoal de alguns magistrados sobre o Direito.

Demonstrou-se, portanto, que os votos dos Ministros Gilmar Mendes e Eros Grau não estão de acordo ao atual Paradigma Moderno, carecendo de legitimidade e fundamentação democrática. Andou bem o Supremo Tribunal Federal em rechaçar a mutação constitucional ao art. 52, inciso X, por ser tal decisão fruto de um momento histórico constitucional em que a legitimidade residia exclusivamente na autoridade do magistrado.

Mais do que entender o fundamento da decisão dos Ministros Gilmar Mendes e Eros Grau, faz-se necessário compreender a negativa dos demais Ministros em seguir esses votos. Afinal, o Pretório Excelso não é fiscal para controlar os atos do Poder Constituinte, não podendo atuar como se fosse o próprio titular desse Poder. Caso procedesse dessa maneira, usurparia a titularidade do povo e colocaria em xeque todo o sistema de direitos e garantias individuais, que parte da supremacia da Magna Carta, fruto da soberania popular, articulada pelo exercício do Poder Constituinte Originário.

\section{REFERÊNCIAS}

CATTONI, Marcelo. Devido processo legislativo. 2. ed. Belo Horizonte: Mandamentos, 2006. $228 \mathrm{p}$.

COURA. Alexandre de Castro. Por uma jurisdição constitucionalmente adequada ao paradigma do Estado Democrático de Direito - reflexões acerca da legitimidade das decisões judiciais e a efetivação dos direitos e garantias fundamentais. In: SIQUEIRA, Julio Pinheiro Homem de e outros. Uma homenagem aos 20 anos da Constituição Brasileira. Florianópolis: Fundação Boiteux, 2008.

GRAU, Eros. Voto do Ministro Eros Grau na Rcl. no 4335. Disponível em: http://www.stf.jus.br/imprensa/pdf/rcl4335eg.pdf>. Acesso em: 10 ago. 2014.

HABERMAS, Jürgen. A Inclusão do outro: Estudos de Teoria Política. Tradução de George Sperber, Paulo Astor Soethe e Milton Camargo Mota. São Paulo: Loyola, 2007. 404 p.

Direito e democracia: entre facticidade e validade. Tradução de Fábio Beno Siebeneichler. 2. ed. Rio de Janeiro: Tempo Brasileiro, 2003. 354 p. v. 1.

HÄBERLE, Peter. Hermenêutica constitucional: A sociedade aberta de intérpretes da Constituição: contribuição para a interpretação pluralista e "procedimental" da Constituição. Tradução de Gilmar Ferreira Mendes. Porto Alegre: Sérgio Antonio Fabris, 1997. 55 p.

Entrevista com Francisco Balaguer Callejón. In: VALADÉS, Diego. (Org.). Conversas acadêmicas com Peter Häberle. São Paulo: Saraiva, 2009, p. 17-68. 
MAUS, Ingeborg. Judiciário como superego da sociedade: o papel da atividade jurisprudencial na sociedade órfã. Tradução: Martônio Lima e Paulo Albuquerque. Novos estudos, CEBRAP, n. 58, p. 183-202, nov. 2000.

MENDES, Gilmar Ferreira. Voto proferido na Reclamação 4335. Disponível em: http://www.stf.jus.br/imprensa/pdf/RCL4335gm.pdf>. Acesso em: 10 ago. 2014.

PRATES, Francisco de Castilho. Identidade constitucional e interpretação no Estado Democrático de Direito: a assunção do risco. In: CATTONI, Marcelo (Org.). Jurisdição e hermenêutica constitucional. Belo Horizonte: Mandamentos, 2004 p. 519-556.

ROSENFELD, Michel. A identidade do sujeito constitucional. Tradução de Menelick de Carvalho Netto. Belo Horizonte: Mandamentos, 2003. 115 p.

STRECK, Lenio Luiz; CATTONI, Marcelo; LIMA, Martonio Mont'Alverne Barreto. A nova perspectiva do Supremo Tribunal Federal sobre o controle difuso: mutação constitucional e limites da legitimidade da jurisdição constitucional. Disponível em: 〈www.ihj.org.br〉. Acesso em: 14 jan. 2010. 